\title{
Class II major histocompatibility complex antigen expression on peripheral blood monocytes in patients with inflammatory bowel disease
}

\author{
K R Gardiner, A D Crockard, M I Halliday, B J Rowlands
}

\begin{abstract}
Macrophage major histocompatibility complex (MHC) class II antigen expression is associated with defective antigen presentation to $\mathbf{T}$ lymphocytes in animals and is predictive of patient outcome after major trauma or sepsis. In this study, class II antigen (HLA-DR and DQ) expression on peripheral blood monocytes was investigated in patients with inflammatory bowel disease in relation to disease activity and outcome. The percentage positivity and fluorescent intensity of expression of HLA-DR and DQ antigens on monocytes were determined in whole blood samples using dual colour immunofluorescence labelling and flow cytometry. Disease activity was assessed using clinical and laboratory indices. There was no significant difference in percentage positivity or fluorescent intensity of class II antigen expression between patients with Crohn's disease, those with ulcerative colitis, and healthy volunteers. The percentage of monocytes displaying HLA-DR positivity was significantly decreased in patients with active ulcerative colitis (active \%: 49.5 (5.6); inactive $\%$ : 78.9 (6.9); $p=0.01$ ). Data expressed as mean (SEM). In patients requiring surgical resection of diseased bowel, the percentage of monocytes displaying HLA-DR positivity $(51.9(4.0) \%)$ was significantly reduced compared with patients receiving medical treatment alone $(81.1 \quad(3.5) \% ; \quad p<0.001)$. Reduced monocyte HLA-DR expression is therefore associated with disease activity and seems to predict outcome in patients with inflammatory bowel disease.
\end{abstract}

(Gut 1994; 35: 511-516)

While a single aetiological agent for inflammatory bowel disease has not been identified, there is evidence that host response to luminal antigens has a role in the ongoing inflammation. There are reports of raised concentrations of circulating antibodies to enteric bacteria ${ }^{12}$ and dietary antigens ${ }^{3}$ and also of cell mediated responses to bacterial antigens in patients with ulcerative colitis and Crohn's disease. ${ }^{45}$ Crucial to the mounting of an immune response is the recognition of the foreign antigens present on such infectious organisms or dietary components. T cells require macrophage cell surface expression of both the foreign antigen and self major histocompatibility complex (MHC) antigens to initiate a response and proliferate. ${ }^{6}$ The result is the generation of $T$ helper cells with subsequent B cell immunoglobulin production and enhanced phagocytosis of the antigen.
The main human histocompatibility antigens, of which there are three classes, were first identified on peripheral blood lymphocytes and therefore named human leucocyte antigens (HLA). Class II antigens contain at least three subsets: HLA-DR, DQ, and DP. . Among these, HLA-DR molecules are dominant and are present primarily on the surface of B lymphocytes, some $\mathrm{T}$ lymphocytes, and on antigen presenting macrophages. Reduced macrophage MHC class II antigen expression is associated with defective antigen presentation to $T$ lymphocytes in animals subjected to haemorrhagic shock. ${ }^{8}$ In addition, expression of HLA-DR on peripheral blood monocytes has been shown to predict patient outcome after major trauma. ${ }^{910}$

It is not clear if a reduction in macrophage class II antigen expression contributes to the impairment in antigen presentation (or poor outcome) or is simply a marker of the initial insult. ${ }^{8-10}$ This study investigated the relation of class II antigen expression by peripheral blood monocytes with disease activity and with outcome in patients with inflammatory bowel disease.

\section{Patients and methods}

PATIENTS AND CONTROLS

The study group consisted of patients, diagnosed as having Crohn's disease or ulcerative colitis on the basis of clinical, radiological, and endoscopic features. Eighteen patients were studied (ulcerative colitis: $n=11$, Crohn's disease: $n=7$ ) with an age range of 15-73 years. Fifteen healthy volunteers, age range 20-55 years, served as controls. No patient or control had received immunosuppressive treatment or had had surgery within the previous three months. This study was approved by the research ethical committee of the Faculty of Medicine, The Queen's University of Belfast.

\section{COLLECTION OF BLOOD}

Venous blood was taken from patients within 24 hours of admission with a symptomatic relapse of inflammatory bowel disease or for follow up colonoscopy. Blood was collected aseptically in sterile and endotoxin free borosilicate glass tubes containing heparin 20 units $/ \mathrm{ml}$ for monocyte HLA-DR and DQ determination. Blood was collected for measurement of acute phase proteins, erythrocyte sedimentation rate, serum albumin concentration, and differential white cell count. 

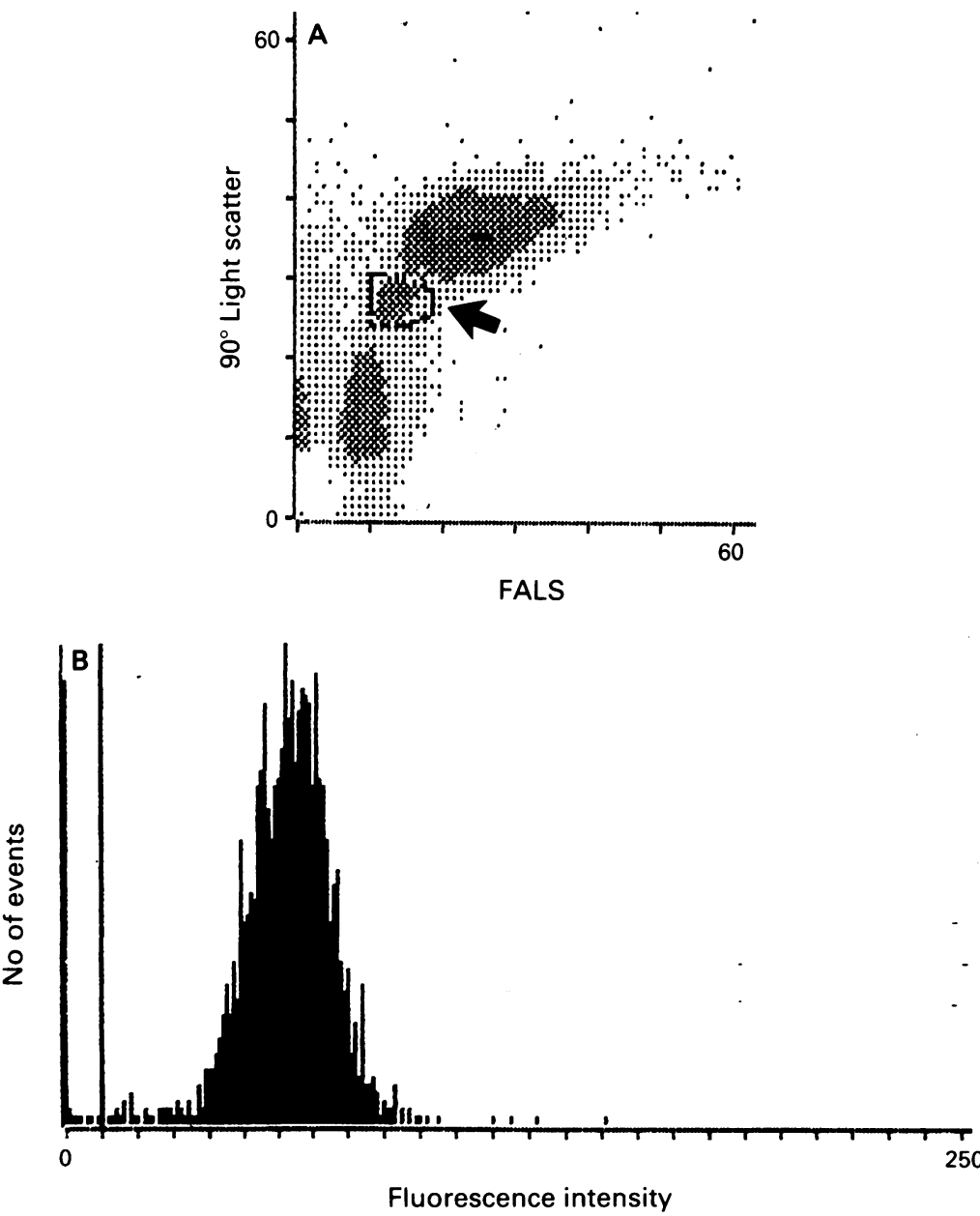

Figure 1: Identification of monocytes by (A) forward and $90^{\circ}$ light scatter signals (FALS); gated monocytic populations shown arrowed, $(B)$ Leu M 3 (CD14) positivity $(95 \%)$ of the gated monocytic population.
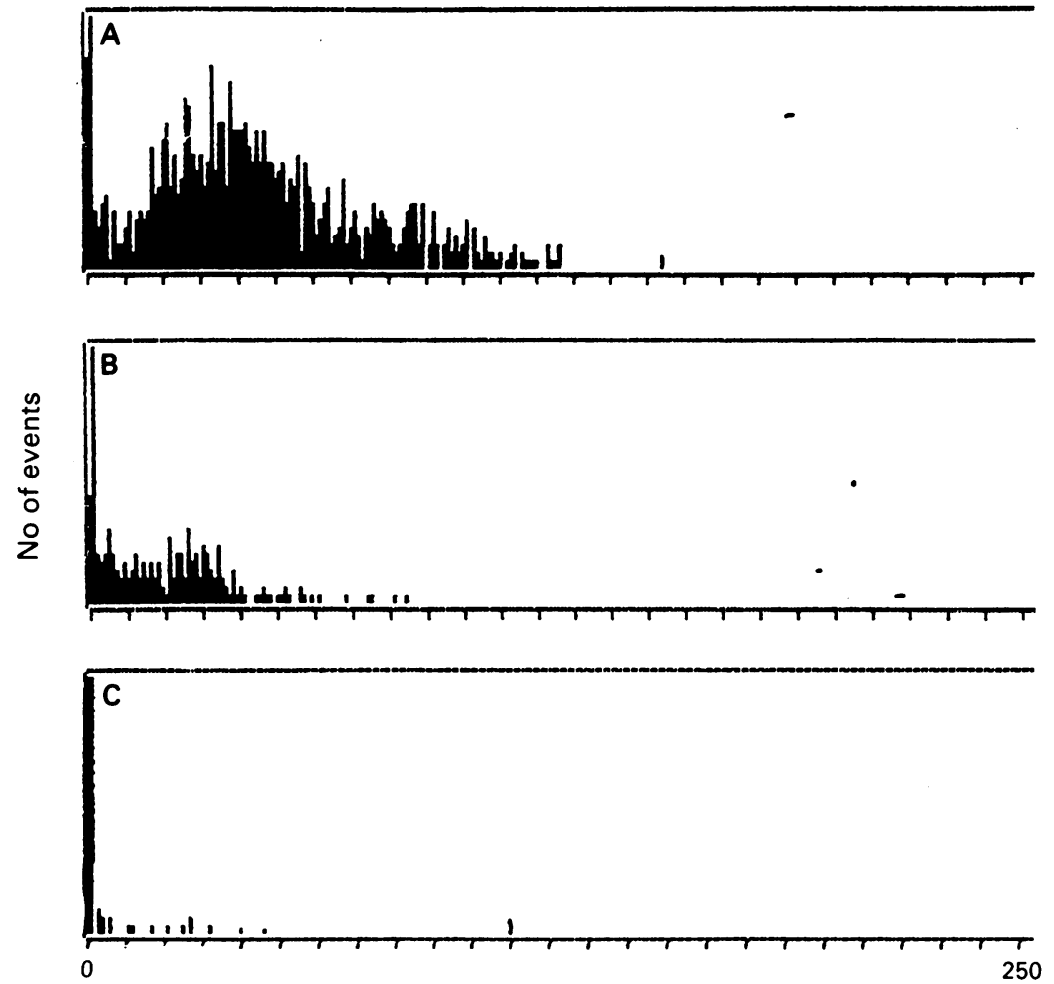

Fluorescence intensity

Figure 2: Fluorescein histogram of $(A) H L A-D R$ and $(B) H L A-D O$ labelled monocytes identified on the basis of light scatter signals and $L$ eu $M 3$ positivity; (C) mouse Ig $G_{1}$-fluorescein isothiocyanate control histogram.
CELL SEPARATION

In a preliminary study, with five healthy volunteers, monocyte expression of HLA-DR and DQ antigens was determined simultaneously in aliquots of whole blood and of a mononuclear cell preparation. Mononuclear cells were separated" from a $20 \mathrm{ml}$ sample of fresh venous blood and resuspended in phosphate buffered saline to give a count of $10 \times 10^{6}$ mononuclear cells $/ \mathrm{ml}$.

\section{IMMUNOFLUORESCENCE STAINING}

The expression of HLA-DR and DQ antigens on monocytes was determined in whole blood (or the mononuclear cell preparation), within two hours of collection, using dual colour immunofluorescent labelling and flow cytometry. Monocytes were identified by direct immunofluorescence staining using phycoerythrin conjugated monoclonal antibody anti-Leu M3 (CD14) (Becton Dickinson, Oxford, UK). This identifies $70-93 \%$ of human peripheral blood monocytes and does not react with lymphocytes. ${ }^{12}$ The expression of HLA-DR and HLA-DQ antigens was determined using fluorescein isothiocyanate conjugated HLA-DR and HLA-DQ monoclonal antibodies (Becton Dickinson, Oxford, UK). Fluorescein isothiocyanate conjugated mouse IgGl and phycoerythrin conjugated mouse IgG2a (Becton Dickinson, Oxford, UK) monoclonal antibodies were used as controls.

To $100 \mu \mathrm{l}$ aliquots of whole blood (or mononuclear cell suspension), were added $10 \mu \mathrm{l}$ of fluorescein isothiocyanate conjugated or phycoerythrin conjugated monoclonal antibody, or both. After a 30 minute incubation at $4^{\circ} \mathrm{C}$, the samples were washed with $2 \mathrm{ml}$ phosphate buffered saline for three minutes at $400 \mathrm{~g}$, before lysis of erythrocytes (whole blood samples only whole blood lysing reagent, Coulter Immunology, Hialeah, FL, USA). The samples were then washed twice as above and fixed in phosphate buffered saline containing $1 \%$ paraformaldehyde. All of the stained preparations were protected from light and stored at $4^{\circ} \mathrm{C}$ until analysis by flow cytometry.

\section{FLOW CYTOMETRY}

Flow cytometric analyses were performed on an EPICS V instrument (Coulter Electronics Inc, Hialeah, Florida) equipped with an argon laser emitting $300 \mathrm{~mW}$ at $488 \mathrm{~nm}$. The instrument was calibrated using Immuno-Check alignment fluorospheres (Coulter Corporation, Hialeah, Florida), before each series of analyses. Monocytes were identified on the basis of forward and $90^{\circ}$ light scatter signals (Fig 1A) confirmed by Leu M3 staining (Fig 1B). HLA-DR (or DQ) expression was measured only on cells that contained positive for Leu M3. For each assay, 1000 monocytes were analysed and single parameter 256 channel log integral green histograms collected. After subtraction of background staining from control samples, the percentage of total sample monocytes (Leu M3-staining cells) that expressed HLA-DR (or DQ), as well as the median channel fluorescent intensity (mcf: a measure of antigen density), was determined (Fig 2). 


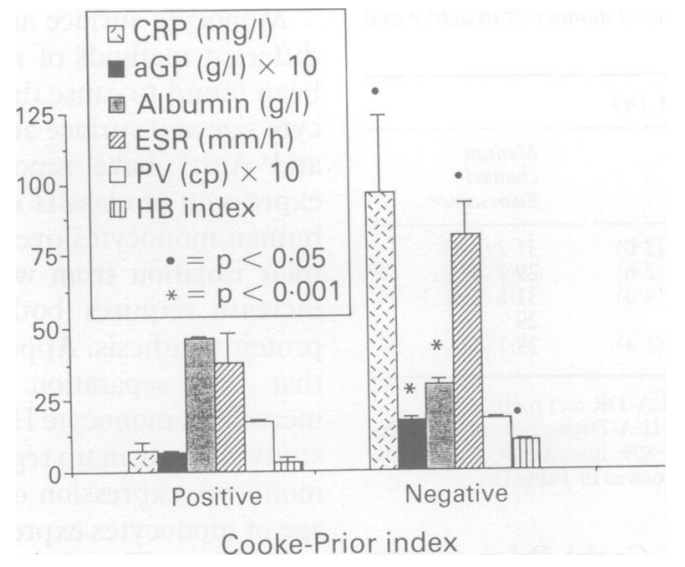

Figure 3: Stratification of disease activity in inflammatory bowel disease patients using Cooke-Prior scores. $C R P=C$ reactive protein; $a G P=$ acid glycoprotein; $E S R=$ erythrocyte sedimentation rate; $P V=$ plasma viscosity; $H B=$ Harvey - Bradshaw

BIOCHEMICAL INDICES OF DISEASE ACTIVITY Serum $\alpha$ 1-acid glycoprotein concentration (normal range $0 \cdot 33-0 \cdot 88 \mathrm{~g} / \mathrm{l}$ ) was determined by rate nephelometry (Beckman-Array analyser); serum $C$ reactive protein concentration (normal $<6 \mathrm{mg} / \mathrm{l}$ ) by precipitin quantitation (Technicon 500 , Technicon Instruments Corp, New York, USA); plasma viscosity (normal range 1.65-1.75 centiPoise) by a capillary method (Coulter Viscometer II, Coulter Electronics Ltd, Luton, UK); serum albumin concentration (normal range $30-45 \mathrm{~g} / \mathrm{l}$ ) by an automated method using bromocresol green; and erythrocyte sedimentation rate ( $\mathrm{mm}$ in first hour) by the standard Westergren method within one hour of collection under identical conditions by one investigator.

INDICES OF DISEASE ACTIVITY

In this study, disease activity was assessed using the Harvey-Bradshaw simple index, ${ }^{13}$ and the laboratory index of Cooke and Prior. ${ }^{14}$

TABLE I HLA-DR and DQ antigen expression by peripheral blood monocytes in whole blood and after monocyte separation

\begin{tabular}{|c|c|c|c|c|}
\hline & \multicolumn{2}{|l|}{$H L A-D R$} & \multicolumn{2}{|l|}{$H L A-D Q$} \\
\hline & $\%$ & $m c f$ & $\%$ & $m c f$ \\
\hline $\begin{array}{l}\text { Whole blood } \\
\text { Mononuclear preparation } \\
\text { Significance }\end{array}$ & $\begin{array}{l}70 \cdot 0(-8 \cdot 7) \\
87 \cdot 3(3.9) \\
p=0.067\end{array}$ & $\begin{array}{l}38 \cdot 2(1 \cdot 6) \\
47 \cdot 4(4 \cdot 2) \\
p=0 \cdot 022^{\star}\end{array}$ & $\begin{array}{c}4 \cdot 0(1 \cdot 3) \\
10 \cdot 4(3 \cdot 8) \\
\mathrm{p}=0 \cdot 004^{\star}\end{array}$ & $\begin{array}{l}25 \cdot 0(1 \cdot 1) \\
25 \cdot 6(0 \cdot 8) \\
\mathrm{p}=0.617\end{array}$ \\
\hline
\end{tabular}

Data expressed as mean $(\mathrm{SEM})(\mathrm{n}=5$ healthy volunteers $) ; \mathrm{mcf}=$ median channel fluorescence; significance ${ }^{\star}$ as shown using paired $t$ test on $\log _{10}$ transformed data.

TABLE II $H L A-D R$ and $D Q$ antigen expression by peripheral blood monocytes in ulcerative colitis (UC) and Crohn's disease $(C D)$

\begin{tabular}{|c|c|c|c|c|c|}
\hline & \multirow[b]{2}{*}{$n$} & \multicolumn{2}{|l|}{$H L A-D R$} & \multicolumn{2}{|l|}{$H L A-D Q$} \\
\hline & & $\%$ & $\begin{array}{l}\text { Median } \\
\text { channel } \\
\text { fluorescence }\end{array}$ & $\%$ & $\begin{array}{l}\text { Median } \\
\text { channel } \\
\text { fluorescence }\end{array}$ \\
\hline $\begin{array}{l}\text { UC } \\
\text { CD } \\
\text { Controls }\end{array}$ & $\begin{array}{r}11 \\
7 \\
15\end{array}$ & $\begin{array}{l}65 \cdot 5(6 \cdot 3) \\
72 \cdot 3(5 \cdot 4) \\
73 \cdot 4(4 \cdot 0)\end{array}$ & $\begin{array}{l}43.4(2 \cdot 6) \\
47 \cdot 4(5 \cdot 9) \\
42 \cdot 3(1 \cdot 4)\end{array}$ & $\begin{array}{r}8 \cdot 3(1 \cdot 8) \\
12 \cdot 1(3 \cdot 6) \\
7 \cdot 6(1 \cdot 4)\end{array}$ & $\begin{array}{l}30 \cdot 4(1 \cdot 3) \\
31 \cdot 4(2 \cdot 5) \\
29 \cdot 7(1 \cdot 2)\end{array}$ \\
\hline
\end{tabular}

Data expressed as mean (SEM); significance: no significant difference between groups for HLA-DR or DQ \% or mcf (analysis of variance).
OUTCOME

Patients were classified into two groups according to outcome at six months after study: (a) those whose disease was in remission (asymptomatic) or under control (receiving acetylsalicylic acid or steroids, or both); and (b) those having had surgical excision of diseased intestine.

\section{CALCULATIONS}

Results are expressed as percentage of total Leu M3 staining monocytes that expressed HLA-DR or DQ and as median channel fluorescence (mcf). Results are displayed as mean (SEM) values. Data analysis was performed on a Macintosh LC personal computer using Student's $t$ test, analysis of variance (ANOVA) and Mann-Whitney U test (Statworks). Probabilities less than 0.05 were considered significant.

\section{Results}

\section{DISEASE ACTIVITY}

Patients with active disease (negative CookePrior score) had significant increases in HarveyBradshaw index, erythrocyte sedimentation rate, and serum concentrations of $C$ reactive protein and $\alpha_{1}$ acid glycoprotein and significantly lower serum albumin concentrations than those with inactive disease (Fig 3).

MONOCYTE CLASS II EXPRESSION IN WHOLE BLOOD AND AFTER MONONUCLEAR SEPARATION IN

HEALTHY VOLUNTEERS

The preparation of a mononuclear cell suspension resulted in a significant increase in the fluorescent intensity (mcf) of monocyte HLA-DR expression and in the percentage of monocytes expressing the HLA-DQ antigen, compared with whole blood samples (Table I). It was concluded that mononuclear cell separation in itself was causing an upregulation in monocyte class II expression, and therefore the whole blood method was chosen for use in the remainder of the studies as a more accurate measure of in vivo class II expression.

\section{MONOCYTE CLASS II EXPRESSION IN PATIENTS} WITH INFLAMMATORY BOWEL DISEASE

There were no significant differences in total or differential white cell counts between IBD patients and healthy volunteers (\% monocytes: IBD $5.5(1.0)$; volunteers $7.9(2.2)$; MannWhitney). There were no significant differences in the monocyte expression of HLA-DR and DQ antigens between patients with ulcerative colitis, those with Crohn's disease, and healthy volunteers (Table II). Patients with active ulcerative colitis had significantly decreased percentage expression of HLA-DR antigens by peripheral blood monocytes compared with patients with inactive ulcerative colitis, active Crohn's disease or with healthy volunteers (Table III). The percentage expression of HLA-DR antigens by peripheral blood monocytes from patients with ulcerative colitis showed a significant positive 
TABLE III $H L A-D R$ and $D Q$ antigen expression by peripheral blood monocytes in active and inactive inflammatory bowel disease

\begin{tabular}{|c|c|c|c|c|c|}
\hline & \multirow[b]{2}{*}{$n$} & \multicolumn{2}{|l|}{$H L A-D R$} & \multicolumn{2}{|l|}{$H L A-D Q$} \\
\hline & & $\%$ & $\begin{array}{l}\text { Median } \\
\text { channel } \\
\text { fluorescence }\end{array}$ & $\%$ & $\begin{array}{l}\text { Median } \\
\text { channel } \\
\text { fluorescence }\end{array}$ \\
\hline $\begin{array}{l}\text { Active UC } \\
\text { Inactive UC } \\
\text { Active CD } \\
\text { Inactive CD } \\
\text { Controls }\end{array}$ & $\begin{array}{r}5 \\
6 \\
6 \\
1 \\
15\end{array}$ & $\begin{array}{l}49 \cdot 5(5 \cdot 6)^{\star} \dagger \\
78 \cdot 9(6 \cdot 9) \\
75 \cdot 2(5 \cdot 4) \\
55 \cdot 2 \\
73 \cdot 4(4 \cdot 0)\end{array}$ & $\begin{array}{l}40 \cdot 0(3 \cdot 9) \\
46 \cdot 3(3 \cdot 2) \\
49 \cdot 3(6 \cdot 7) \\
36 \\
42 \cdot 3(1 \cdot 4)\end{array}$ & $\begin{array}{c}5 \cdot 5(2 \cdot 0) \\
10 \cdot 7(2 \cdot 6) \\
13 \cdot 2(4 \cdot 0) \\
5 \cdot 4 \\
7 \cdot 6(1 \cdot 4)\end{array}$ & $\begin{array}{l}31 \cdot 2(2 \cdot 4) \\
29 \cdot 7(1 \cdot 5) \\
31 \cdot 8(2 \cdot 9) \\
29 \\
29 \cdot 7(1 \cdot 2)\end{array}$ \\
\hline
\end{tabular}

Data expressed as mean (SEM); significance: HLA-DR\% $p=0 \cdot 019$; HLA-DR mcf $p=0 \cdot 347$, HLA-DQ\% $\mathrm{p}=0 \cdot 267$, HLA-DQ mcf $\mathrm{p}=0.885$ (analysis of variance); HLA-DR\%: control $v$ inactive UC $\mathrm{p}=0.681$; control $v$ active UC $\mathrm{p}=0.006 \dagger$, control $v$ active $C D \mathrm{p}=0.809$; inactive UC $v$ active UC $\mathrm{p}=0 \cdot 01^{\star}$; active UC $v$ active $C D \mathrm{p}=0.01^{\star}$ (Student's $t$ test). Abbreviations as in Table II.

correlation with their Cooke-Prior scores (Fig 4).

\section{RELATION BETWEEN MONOCYTE CLASS II} EXPRESSION AND TREATMENT IN PATIENTS WITH IBD

Eight patients had intestinal resection within six months of initial assessment (Table IV). Two of these resections were semi-elective being performed for longterm ill health; the remainder were urgent or emergency operations. In these patients, the percentages of peripheral blood monocytes displaying HLA-DR and DQ positivity were signiicantly lower than the values recorded for patients who received medical treatment alone $(\mathrm{n}=10)$ (Fig 5). There was also a significant reduction in fluorescent intensity of HLA-DR expression by monocytes in patients who subsequently had surgery for their disease.

\section{Discussion}

The macrophage is considered to be the main cell responsible for the presentation of foreign antigens to lymphocytes. ${ }^{15}$ Snyder and Unanue ${ }^{16}$ have shown a very good correlation between levels of expression of immune associated (Ia) antigens (the murine equivalent to HLA-D antigens) by murine macrophages and the capacity to present antigens to lymphocytes. In addition, antibodies to Ia antigens have been shown to inhibit antigen presentation by murine macrophages. ${ }^{17}$ In humans, immune associated antigen expression (HLA-DR) is also required for the presentation of foreign antigen. ${ }^{18}$ The determination of monocyte HLA-DR expression may therefore provide a measure of the body's ability to mount an adequate immune response to invading micro-organisms. ${ }^{19}$

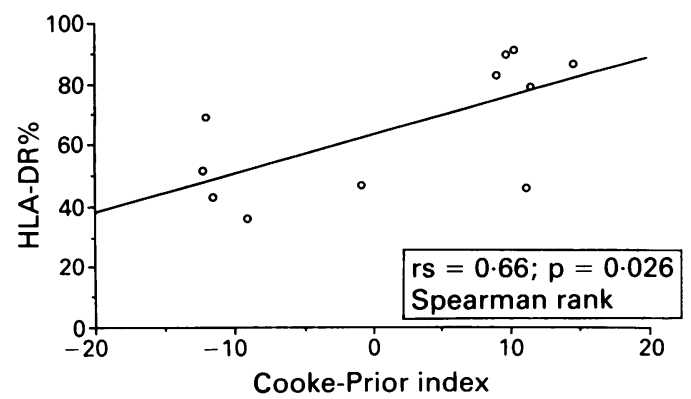

Figure 4: Relation between $H L A-D R$ positivity and Cooke-Prior score in ulcerative colitis. $r s=0.66 ; p=0.026$ Spearman rank test.
Monocyte surface antigens are not stable and different methods of monocyte separation have been found to cause disparate changes in monocyte size and surface antigen expression. ${ }^{20}$ Smith and Ault $^{21}$ have reported an increase in the expression of class II antigens on the surface of human monocytes over the first few hours after their isolation from whole blood and that this increase requires both metabolic energy and protein synthesis. Appel et $a l^{22}$ have also reported that cell separation causes a physiological increase in monocyte HLA-DR expression. This study showed an up regulation in the intensity of monocyte expression of HLA-DR and percentage of monocytes expressing HLA-DQ after cell separation. The assay of HLA-DR and DQ expression in whole blood by dual colour immunofluorescence staining, therefore, permits a more accurate assessment of in vivo monocyte class II expression.

Using the whole blood dual colour immunofluorescent labelling technique, $73.4(4.0) \%$ of monocytes in the healthy volunteers were found to express HLA-DR and $7.6(1.4) \%$ expressed HLA-DQ. This is in keeping with the studies of Hersham et al, ${ }^{1023}$ which have reported that $70-100 \%$ of peripheral blood monocytes express HLA-DR in a control population.

Patients who had received corticosteroid or other immunosuppressant treatment were excluded from this study, as in vitro studies have shown corticosteroid induced inhibition of murine macrophage MHC antigen expression and antigen presentation. ${ }^{16}$ Patients who had recently had surgery were also excluded as early depression of monocyte class II antigen expression has been reported after elective abdominal surgery. ${ }^{24}$ This study has shown that as a group, patients with IBD did not have significantly different percentage or intensity of expression of HLA-DR or DQ antigens by their peripheral blood monocytes from healthy controls.

In this study, the Cooke-Prior index successfully identified active and inactive groups (significantly different acute phase response and Harvey-Bradshaw clinical indices). The percentage of peripheral blood monocytes displaying HLA-DR positivity was significantly lower in patients with active ulcerative colitis (49.5 $(5 \cdot 6) \%)$ than in those with inactive disease $(78.9(6.9) \%)$. In addition, HLA-DR expression was found to be negatively correlated with disease activity (using the Cooke-Prior index) in patients with ulcerative colitis. Reduced expression of HLA-DR by peripheral blood monocytes has also been reported in patients with major sepsis, postoperative infection, and major trauma. ${ }^{22-24}$ In addition, an association between decreased monocyte HLA-DR expression and active disease has been described in systemic lupus erythematosus, tuberculosis, and Hodgkin's disease. ${ }^{25-27}$

In patients ultimately requiring surgical resection of diseased bowel, the percentage of monocytes displaying HLA-DR and DQ positivity on initial assessment was significantly reduced compared with that of patients responding to medical treatment. The ability of peripheral blood monocytes to express the HLA-DR has been shown to be predictive of patient 


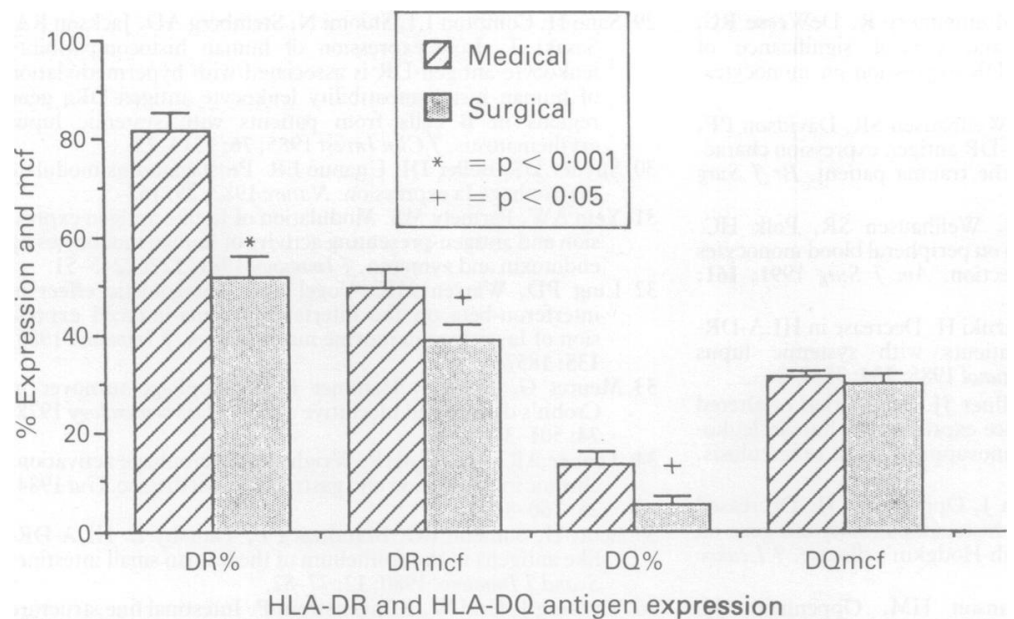

Figure 5: HLA-DR and DQ expression by peripheral blood monocytes as predictors of surgery in inflammatory bowel disease. $m c f=$ median channel fluorescence.

outcome in postoperative sepsis and after major injury. ${ }^{9} 1023$

Various explanations have been put forward to explain the decreased monocyte expression of HLA-DR in other diseases: lower plasma concentrations of, or impaired monocyte susceptibility to circulating interferon $\gamma^{28}$; blockage of surface antigens by autoantibodies causing an apparent reduction in HLA-DR molecules ${ }^{29}$; internalisation of HLA-DR antigen ${ }^{24}$; monocyte dysfunction with reduced synthesis of HLA-DR ${ }^{25}$; consumption of HLA-DR positive monocytes in the periphery ${ }^{25}$; or influx of immature cells that are low HLA-DR expressors into the peripheral blood. ${ }^{24}$ In addition, there is evidence that mediators such as prostaglandins, glucocorticoids, endotoxin, and interferons $\alpha$ and $\beta$ can down regulate monocyte Ia antigen expression. ${ }^{160-32}$

In patients with IBD, the decreased monocyte HLA-DR expression seen may be a result of a loss of circulating DR positive monocytes into the gut (wall or lumen) or an increased monocyte turnover. ${ }^{33}$ Macrophages comprise about $10 \%$ of the mononuclear cell population of human intestinal mucosa. Most of these cells are recruited from blood monocytes, with a negligible contribution from macrophage proliferation. ${ }^{34}$ HLA-DR positive, macrophage like

TABLE IV Surgical outcomes

\begin{tabular}{|c|c|c|c|c|c|c|c|}
\hline & & \multicolumn{3}{|l|}{ Surgery } & \multirow{2}{*}{\multicolumn{2}{|c|}{ Indices }} & \multirow{3}{*}{$\begin{array}{l}H L A \\
D R \%\end{array}$} \\
\hline & & \multirow[b]{2}{*}{ What? } & \multirow{2}{*}{$\begin{array}{l}\text { When? } \\
\text { (days) }\end{array}$} & \multirow[b]{2}{*}{ Why? } & & & \\
\hline & & & & & $C-P$ & $H-B$ & \\
\hline 1 & $\mathrm{CD}$ & Left hemicolectomy & 52 & $\begin{array}{l}\text { Failed medical } \\
\text { treatment }\end{array}$ & $-14 \cdot 1$ & 8 & $57 \cdot 0$ \\
\hline 2 & $\mathrm{CD}$ & $\begin{array}{l}\text { Right hemicolectomy }+ \\
\text { drainage of abscess }\end{array}$ & 2 & $\begin{array}{l}\text { Tender abdominal } \\
\text { mass }\end{array}$ & $-25 \cdot 8$ & 9 & $64 \cdot 3$ \\
\hline 3 & $\mathrm{CD}$ & $\begin{array}{l}\text { Total abdominal } \\
\text { colectomy }\end{array}$ & 5 & Toxic megacolon & $-26 \cdot 7$ & 17 & $70 \cdot 4$ \\
\hline 4 & UC & Proctocolectomy & 14 & $\begin{array}{l}\text { Failed medical } \\
\text { treatment }\end{array}$ & $-12 \cdot 3$ & 8 & $51 \cdot 6$ \\
\hline 5 & UC & $\begin{array}{l}\text { Total abdominal } \\
\text { colectomy }\end{array}$ & 62 & $\begin{array}{l}\text { Failed medical } \\
\text { treatment }\end{array}$ & $-9 \cdot 2$ & 13 & $36 \cdot 2$ \\
\hline 6 & UC & $\begin{array}{l}\text { Restorative } \\
\text { proctocolectomy }\end{array}$ & 13 & Chronic ill health & -0.8 & 10 & $47 \cdot 0$ \\
\hline 7 & UC & $\begin{array}{l}\text { Total abdominal } \\
\text { colectomy }\end{array}$ & 31 & Toxic megacolon & $-11 \cdot 6$ & 9 & $43 \cdot 2$ \\
\hline 8 & UC & $\begin{array}{l}\text { Total abdominal } \\
\text { colectomy }\end{array}$ & 84 & Chronic ill health & $11 \cdot 2$ & 2 & $45 \cdot 7$ \\
\hline
\end{tabular}

Where: $\mathrm{H}-\mathrm{B}=$ Harvey-Bradshaw scores; $\mathrm{C}-\mathrm{P}=$ Cooke-Prior scores. Abbreviations in Table II. cells have been identified within the lamina propria of the small and large intestine. ${ }^{35}$ Thyberg et al have reported an increase in the number of macrophages in the intestinal mucosa of patients with Crohn's disease. ${ }^{36}$

The significance of decreased peripheral blood monocyte HLA-DR expression in IBD patients is not known, but could imply an impaired ability to eliminate foreign antigen, which may permit systemic endotoxaemia and bacteraemia, and lead to disease relapse. An alternative explanation is that class II expression is simply a marker of the severity of the inflammatory response. Further information may be obtained in these patients by serial measurement of monocyte HLA-DR expression as has been found of value in trauma patients. ${ }^{23}$

This work was supported by a grant from the Eastern Health and Social Services Board, Northern Ireland. We thank the research fellows and staff of the department of surgery for donating the control blood specimens.

Presented at the British Society of Gastroeneterology Meeting on 9 September 1992 at the University of Warwick.

1 Tabaqchali S, O'Donoghue DP, Bettelheim KA. Escherichia coli antibodies in patients with inflammatory bowel disease. Gut 1978; 19: 108-13.

2 Matthews N, Mayberry JF, Rhodes J. Agglutinins to bacteria in Crohn's disease. Gut 1980; 21 : 376-80.

3 Falchuk KR, Isselbacher KJ. Circulating antibodies to bovine albumin in ulcerative colitis and Crohn's disease. Gastroenterology 1976; 70: 5-8.

4 Bull DM, Ignaezak TF. Enterobacterial common antigeninduced lymphocyte reactivity in inflammatory bowel disease. Gastroenterology 1973; 64: 43-50.

5 Eckhardt R, Heimisch M, Meyer zum Buschenfelde KH Cellular immune reactions against common antigen, small intestine and colon antigen in patients with Crohn's disease, ulcerative colitis and cirrhosis of the liver. Scand $\mathcal{F}$ Gastroenterol 1976; 11: 49-54.

6 Benacerraf B. Role of MHC products in immune regulation. Science 1981; 212: 1229-38.

7 Auffray C, Kuo J, DeMars R, Strominger JL. A minimum of four human class II $\alpha$-chain genes are encoded in the HLA region of chromosome 6 . Nature 1983; 304: 174-7.

8 Ayala A, Perrin MM, Chaudry IH. Defective macrophage antigen presentation following hemorrhage is associated with the loss of MHC class II (Ia) antigens. Immunology 1990; 70: 33-9.

9 Polk HC, George CD, Wellhausen SR, Cost K, Davidson PR, Regan MP, et al. A systematic study of host defense processes in badly injured patients. Ann Surg 1986; 204: processes

10 Hershman MJ, Cheadle WG, Kuftinec D, Polk HC, George CD. An outcome predictive score for sepsis and death following injury. Injury 1988; 19: 263-6.

11 Boyum A. A one stage procedure for isolation of granulocytes and lymphocytes from human blood. Scand $\mathcal{f}$ Clin Lab Invest 1968; 21 (suppl 97): 51-76.

12 Dimitriu-Bona A, Burmester GR, Waters SJ, Winchester RJ. Human mononuclear phagocyte differentiation antigens. I. Patterns of antigenic expression on the surface of human monocytes and macrophages defined by monoclonal antibodies. F Immunol 1983; 130: 145-52.

13 Harvey RF, Bradshaw JM. A simple index of ulcerative colitis activity. Lancet 1980; i: 514.

14 Cooke WT, Prior P. Determining disease activity in inflammatory bowel disease. 7 Clin Gastroeneterol 1984; 6: 17-25.

15 Unanue ER. The regulation of lymphocyte functions by the macrophage. Immunol Rev 1978; 40: 227-55.

16 Snyder DS, Unanue ER. Corticosteroids inhibit murine macrophage Ia expression and interleukin 1 production. f Immunol 1982; 129: 1803-5.

17 Thomas DW, Yamashito U, Shevach EM. Nature of the antigenic complex recognized by T lymphocytes. IV. Inhibition of antigen-specific $T$ cell proliferation by antibodies to stimulator macrophage Ia antigens. F Immunol 1977; 119: 223-6.

18 Engleman EG, Charron DJ, Benike CJ, Stewart GJ. Ia antigen on peripheral blood mononuclear leukocytes in man. I. Expression, biosynthesis, and function of HLA-DR antigen on non-T cells. F $\exp M e d$ 1980; 152: 99-113S

19 Ertel W, Meldrum DR, Morrison MH, Ayala A, Chaudry IH. Immunoprotective effect of a calcium channel blocker on macrophage antigen presentation function, major histocompatibility class II antigen expression, and interleukin-1 synthesis after hemorrhage. Surgery 1990; 108: 154-60.

20 Triglia T, Burns GF, Werkmeister JA. Rapid changes in surface antigen expression by blood monocytes cultured in surface antigen expression by blood monocytes cultured in
suspension or adherent to plastic. Blood 1985; 65: 921-8.

21 Smith BR, Ault KA. Increase of surface Ia-like antigen expression on human monocytes independent of antigenic stimuli. F Immunol 1981; 127: 2020-7. 
22 Appel SH, Wellhausen SR, Montgomery R, DeWeese RC, Polk HC. Experimental and clinical significance of Polk HC. Experimental and clinical significance of f Surg Res 1989; 47: 39-44.

23 Hershman MJ, Cheadle WG, Wellhausen SR, Davidson PF, Polk HC Jr. Monocyte HLA-DR antigen expression characterizes clinical outcome in the trauma patient. Br $\mathcal{F}$ Surg 1990; 77: 204-7.

24 Cheadle WG, Hershman MJ, Wellhausen SR, Polk HC. HLA-DR antigen expression on peripheral blood monocytes correlates with surgical infection. Am f Surg 1991; 161: 639-45.

25 Shirakawa F, Yamashita U, Suzuki H. Decrease in HLA-DRpositive monocytes in patients with systemic lupus erythematosus (SLE). F Immunol 1985; 134: 3560-2.

26 Tweardy DJ, Schacter BZ, Ellner JJ. Association of altered dynamics of monocyte surface expression of human leukocyte antigen DR with immunosuppression in tuberculosis. f Infect Dis 1984; 149: 31-7.

27 Nagai H, Fisher RI, Cossman J, Oppenheim JJ. Decreased expression of class II major histocompatibility antigens on expression of class II major histocompatibility antigens on
monocytes from patients with Hodgkin's disease. 7 Leukoc Biol 1986; 39: 313-21.

28 Sztein MB, Steeg PS, Johnson HM, Oppenheim JJ. Regulation of human peripheral blood monocyte DR antigen expression in vitro by lymphokines and recombinant interferons. $\mathcal{F}$ Clin Invest 1984; 73: 556-65.
29 Sano H, Compton LJ, Shiomi N, Steinberg AD, Jackson RA, Sasaki T. Low expression of human histocompatibility leukocyte antigen-DR is associated with hypermethylation leukocyte antigen-DR is associated with hypermethylation
of human histocompatibility leukocyte antigen-DRa gene of human histocompatibility leukocyte antigen-DRa gene
regions in B cells from patients with systemic lupus erythematosus. F Clin Invest 1985; 76: 1314-22.

30 Snyder DS, Beller DI, Unanue ER. Prostaglandins modulate macrophage Ia expression. Nature 1982; 29: 163-5.

31 Yem AW, Parmely MS. Modulation of Ia-like antigen expression and antigen-presenting activity of human monocytes by endotoxin and zymosan. F Immunol 1981; 127: 2245-51.

32 Ling PD, Warren MK, Vogel SN. Antagonistic effect of interferon-beta on the interferon-gamma-induced expression of Ia antigen in murine macrophages. 7 Immunol 1985; 135: $1857-63$.

33 Meuret G, Bitzi A, Hammer B. Macrophage turnover in Crohn's disease and ulcerative colitis. Gastroenterology 1978; 74: 501-3.

34 Tanner AR, Arthur MJP, Wright R. Macrophage activation, chronic inflammation and gastrointestinal disease. Gut 1984; chronic inf $760-83$.

35 Scott H, Solheim BG, Brandtzaeg P, Thorsby E. HLA-DRlike antigens in the epithelium of the human small intestine. Scand F Immunol 1980; 12: 77-82.

36 Thyberg J, Graf W, Klingenstrom P. Intestinal fine structure in Crohn's disease. Lysosomal inclusions in epithelial cells and macrophages. Virchows Arch Pathol Anat 1981; 39: $141-52$. 